\section{Synthesis and Solubility of (Mono-) End-Functionalized Poly(2-hydroxyethyl methacrylate-g-ethylene glycol) Graft Copolymers with Varying Macromolecular Architectures}

\section{Dong Zhang, Celia Macias, and Christine Ortiz*}

Department of Materials Science and Engineering, Massachusetts Institute of Technology,

77 Massachusetts Avenue, Cambridge, Massachusetts 02139

Received April 5, 2004

Revised Manuscript Received June 21, 2004

\section{Introduction}

Comblike, side-chain graft copolymers, also called molecular bottle brushes, are branched macromolecules composed of an array of side chains attached to a main chain. Such a motif exists in biology; for example, aggrecan macromonomers which provide the compressive stiffness of cartilage tissue, have a protein core backbone and chondroitin sulfate glycosaminoglycan polysaccharide side chains spaced $2-4 \mathrm{~nm}$ apart. ${ }^{1}$ Recently, there has been a large interest in theoretically studying such systems, ${ }^{2}$ as well as preparing analogous synthetic macromolecules ${ }^{3}$ due to their ability to exhibit a broad array of unique conformations ${ }^{4}$ and nanomechanical properties ${ }^{5,6}$ including, in many cases, stimulus responsiveness. ${ }^{7}$ Property control can be achieved via the choice of side chain and main chain chemical structures, as well as the macromolecular architecture (e.g., side chain graft density, length, and distribution along the main chain) to tailor entropic, excluded volume, electrostatic, and other noncovalent interactions. Precise design for particular applications will require the synthesis of well-defined structural libraries in conjunction with theoretical and experimental studies of intra- and intermolecular interactions, thus facilitating a detailed understanding of fundamental nanoscale structure-property relationships.

Recently, we reported the synthesis, characterization, and single macromolecule elasticity measurements of a neutral (mono-) end-functionalized graft copolymer, thiol-terminated poly(2-hydroxyethyl methacrylate-gethylene glycol) or SH-poly(HEMA-g-EG) with a $1 \%$ PEG (poly(ethylene glycol)) graft density ${ }^{6}$ via the atom transfer radical polymerization (ATRP) method $^{8}$ with protecting group chemistry. ${ }^{9}$ (Mono-) end-functionalization provides the ability to chemically end-graft these polymers to surfaces ${ }^{6}$ and small structures (e.g., nanoparticles, nanofibers, etc.) in a well-defined manner. Expanding upon this methodology, the first goal of this research was to synthesize a library of water-soluble SH-poly(HEMA-g-EG) graft copolymers with varying macromolecular architecture; i.e., PEG and PHEMA (poly(2-hydroxyethyl methacrylate)) molecular weights, EG/HEMA mole ratios, and PEG side chain graft density. PEG and PHEMA were chosen as the model systems since they are each individually known to exhibit unique interactions in aqueous environments. ${ }^{10,11}$ For example, PEG exhibits a hydrogen-bonded, waterbound, contracted, helical trans-trans-gauche local

\footnotetext{
* Corresponding author. E-mail: cortiz@mit.edu.
}

conformation, ${ }^{12}$ and PHEMA has been suggested to have a significant amount of bound structured water. ${ }^{13}$ Hence, both are technologically important materials used extensively for biomedical engineering applications, since such unique and strong interactions with water are likely to be a major contributor to bioinertness. ${ }^{14}$ Aside from the potential to create surfaces with improved biocompatibility, PEG/PHEMA graft copolymers also have potential for applications in areas such as single macromolecule nanomechanical design (control of molecular elasticity) and as nanoreactors for nanoparticle preparation. ${ }^{6,15-20}$ The second goal of this study was to establish the relationship between macromolecular architecture and composition with aqueous solubility, as quantified by the cloud point temperature in dilute solution, thus providing insight into the nature of macromolecular intra- and intermolecular interactions.

\section{Experimental Section}

Synthesis and Characterization. SH-poly(HEMA-g-EG) graft copolymers were prepared in a manner similar to that described previously ${ }^{6}$ by ATRP using $\mathrm{CuBr} / 2$-(2,4-dinitrophenylthio)ethyl 2-bromo-2-methylpropionate initiator with the following modifications. For the synthesis of the SH-poly(HEMA-g-EG) $)_{106 K}$, SH-poly(HEMA-g-EG) ${ }_{87 \mathrm{~K}}$, and SH-PHEMA ${ }_{61 \mathrm{~K}}$ $34 \mathrm{~g}(0.016 \mathrm{~mol}), 64 \mathrm{~g}(0.031 \mathrm{~mol})$, and $0 \mathrm{~g}(0 \mathrm{~mol})$ of $\mathrm{PEG}_{2080}$ were employed, respectively. The numerical subscript in the abbreviated polymer name label refers to the number-average molecular weight, $M_{\mathrm{n}}$, of the graft copolymer in $\mathrm{g} / \mathrm{mol}$ and "K" is an abbreviation for 1000 , as determined by ${ }^{1} \mathrm{H}$ nuclear magnetic resonance (NMR). For the synthesis of the SH-poly(HEMA-g-EG) ${ }_{142 \mathrm{~K}}, \mathrm{PEG}_{1100}(34 \mathrm{~g}, 0.031 \mathrm{~mol})$ was used and a reaction solvent of water $(34 \mathrm{~g}, 1.9 \mathrm{~mol})$. For the synthesis of the SH-poly(HEMA-g-EG) ${ }_{122 \mathrm{~K}}$ and SH-poly(HEMA-g-EG) $)_{54 \mathrm{~K}}$, $\mathrm{PEG}_{475}(15 \mathrm{~g}, 0.032 \mathrm{~mol}$ and $30 \mathrm{~g}, 0.063 \mathrm{~mol}$, respectively) was used with the reaction solvent being water $(12.5 \mathrm{~g}, 0.69 \mathrm{~mol})$. The 2,4-dinitrophenyl protecting end group was removed at the end of the reaction using 2-mercaptoethanol yielding the thiol-terminated form of the polymer, as described previously. ${ }^{6}$ Characterization was accomplished via ${ }^{1} \mathrm{H}$ NMR using a Varian Inova-501 instrument in methanol- $d_{4}$ solvents. Chemical shifts $(\delta)$ were reported in ppm concentrations downfield from an internal tetramethylsilane reference.

Cloud Point Temperature Measurements. Each polymer (1 mg) was dissolved in $1 \mathrm{~mL}$ of phosphate buffered saline solution with an ionic strength of $0.15 \mathrm{M}$ and $\mathrm{pH} 7.4$ and was stirred continuously with a magnetic stirrer for up to $5 \mathrm{~h}$ at room temperature. A home-built cloud point apparatus was employed for assessing solubility. A $670 \mathrm{~nm} 1 \mathrm{~mW}$ handheld laser pointer (elliptical spot shape of $\sim 1 \mathrm{~mm} \times 2 \mathrm{~mm}$ ) was shone through the solution onto a Newport photodiode. When the sample was clear, the detector produced $\sim 1.5 \mu \mathrm{A}$ of current which was amplified by a custom built transconductance amplifier (Analog Devices model AD549L FET input operational amplifier with a $1 \mathrm{M} \Omega$ feedback resistor, bandwidth is dc to $100 \mathrm{kHz}$ ) to a level of $1.5 \mathrm{~V}$. The diode current preamp output voltage was measured by a 6.5 digit resolution HP model $3455 \mathrm{~A} \mathrm{DMM}$ on the $10 \mathrm{~V}$ range (readout noise $\sim 0.01 \%$ ). The resolution of the voltmeter was much greater than the laser diode power level noise limit which was $\sim 0.1 \%$. The voltmeter averages the laser noise due to its rate of $\sim 2$ readings per second. The cuvette sample temperature control chamber was an $\mathrm{Al}$ block mounted to two $50 \mathrm{~W}$ thermoelectric heater/cooler modules on each side. A Newport CNi16D44C24 was used to program the cuvette temperature. The temperature was monitored by an HP 3455A DMM using a type " $k$ " thermocouple probe (noise $\sim 0.005^{\circ} \mathrm{C}$ and accuracy was $\sim 1^{\circ}$ ) and battery powered amplifier made by John Fluke. The 
Table 1. Characterization of Thiol-Terminated Poly(2-hydroxyethyl methacrylate) (SH-PHEMA $61 \mathrm{~K})$ and Poly(2-hydroxyethyl methacrylate-g-ethylene glycol) (SH-poly(HEMA-g-EG)) Graft Copolymers Synthesized in This Study and Reported Previously ${ }^{6}$ by ${ }^{1} \mathrm{H}$ Nuclear Magnetic Resonance (NMR)

\begin{tabular}{|c|c|c|c|c|c|c|c|c|c|c|c|}
\hline polymer $^{a}$ & $\begin{array}{l}\text { MW } \\
\text { PEG }\end{array}$ & $\begin{array}{c}M_{\mathrm{n}} \\
(\mathrm{kg} / \mathrm{mol}) \\
\mathrm{NMR}\end{array}$ & $\begin{array}{c}\text { PEG } \\
(\%) \\
\text { NMR }\end{array}$ & $\begin{array}{l}N_{\text {PEG }} \\
\text { NMR }\end{array}$ & $\begin{array}{c}\mathrm{DP}_{\mathrm{n}, \mathrm{EG}} \\
\mathrm{NMR}\end{array}$ & 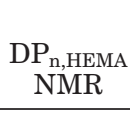 & $\begin{array}{c}\mathrm{DP}_{\mathrm{n}, \mathrm{EG}} / \\
\mathrm{DP}_{\mathrm{n}, \mathrm{HEMA}}\end{array}$ & $d_{\mathrm{PEG}}$ & $\begin{array}{c}L_{\text {contour }} \\
\text { PHEMA } \\
(\mathrm{nm})\end{array}$ & $\begin{array}{c}L_{\text {contour }} \\
\text { PEG } \\
(\mathrm{nm})\end{array}$ & $\begin{array}{l}\mathrm{CP} \\
\left({ }^{\circ} \mathrm{C}\right)\end{array}$ \\
\hline SH-PHEMA $_{61 \mathrm{~K}}$ & 0 & 61 & 0 & 0 & 0 & 469 & 0 & 0 & 144 & 0 & \\
\hline SH-poly(HEMA-g-EG) $)_{120 \mathrm{~K}^{6}}$ & 2080 & 120 & 1 & 8 & 360 & 794 & 0.4 & 27.2 & 245 & 20 & \\
\hline SH-poly(HEMA-g-EG) ${ }_{16 \mathrm{~K}^{6}}$ & 2080 & 16 & 1 & 1 & 45 & 111 & 0.4 & 17.0 & 34 & 20 & \\
\hline SH-poly(HEMA-g-EG) ${ }_{122 \mathrm{~K}}$ & 475 & 122 & 14 & 87 & 680 & 621 & 1.1 & 2.2 & 191 & 5 & 45 \\
\hline SH-poly(HEMA-g-EG) $)_{54 \mathrm{~K}}$ & 475 & 54 & 23 & 52 & 407 & 226 & 1.8 & 1.3 & 70 & 5 & 62 \\
\hline SH-poly(HEMA-g-EG) $)_{142 \mathrm{~K}}$ & 1100 & 142 & 16 & 74 & 1630 & 464 & 3.5 & 1.9 & 143 & 11 & $>70$ \\
\hline SH-poly(HEMA-g-EG) $)_{106 \mathrm{~K}}$ & 2080 & 106 & 4 & 20 & 886 & 497 & 1.8 & 7.3 & 153 & 20 & $\sim 67$ \\
\hline SH-poly(HEMA-g-EG) $)_{87 \mathrm{~K}}$ & 2080 & 87 & 10 & 26 & 1152 & 257 & 4.5 & 2.9 & 79 & 20 & $>70$ \\
\hline
\end{tabular}

${ }^{a}$ The numerical subscript in the abbreviated polymer name labels refer to the number-average molecular weight, $M_{\mathrm{n}}$, of the graft copolymer in $\mathrm{g} / \mathrm{mol}$ and " $\mathrm{K}$ " is an abbreviation for 1000, MW $\mathrm{PEG}$ is the known molecular weight of each PEG chain, PEG \% is the PEG graft density which is defined as $N_{\mathrm{PEG}} / \mathrm{DP}_{\mathrm{n}, \mathrm{HEMA}}, N_{\mathrm{PEG}}$ is the average number of PEG chains per PHEMA chain, DP $\mathrm{n}$ is the numberaverage degree of polymerization, $d_{\mathrm{PEG}}$ is the average HEMA contour length between neighboring PEG chains, $L_{\text {contour }}$ is the average contour length calculated from the known molecular weights, and CP is the cloud point temperature.

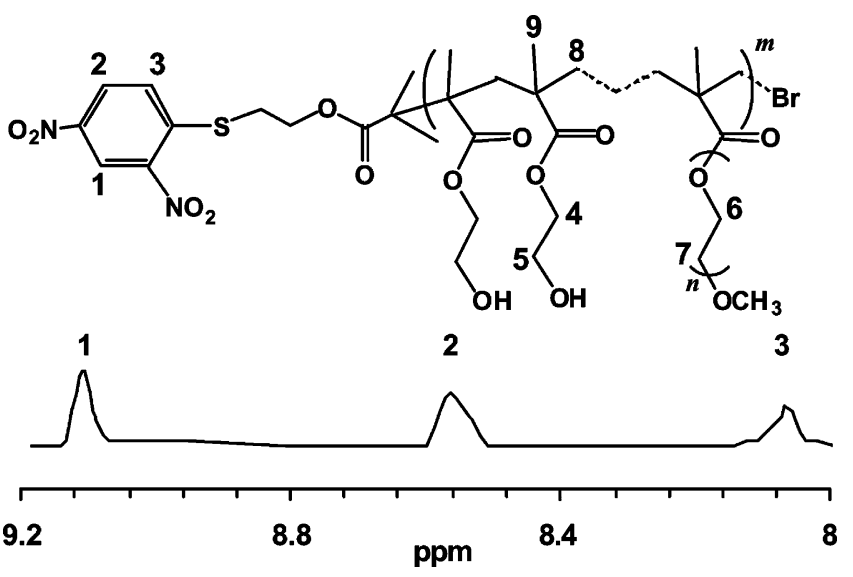

Figure 1. Chemical structure (top) and ${ }^{1} \mathrm{H}$ nuclear magnetic resonance (NMR) spectra in methanol- $d_{4}$ (bottom) showing the characteristic 2,4-dinitrophenyl protecting end group peaks between $\delta=7.8-9.2 \mathrm{ppm}$ for thiol-protected poly(2-hydroxyethyl methacrylate-g-ethylene glycol) or poly(HEMA-g-EG) 54K where the numerical subscript in the abbreviated polymer name labels refer to the number-average molecular weight, $M_{\mathrm{n}}$, of the graft copolymer in $\mathrm{g} / \mathrm{mol}$ and " $\mathrm{K}$ " is an abbreviation for 1000 . The peak numbers labeled on the ${ }^{1} \mathrm{H}$ NMR spectrum correspond to the protons labeled in the chemical structure.

output of the temperature preamp module was connected to the input of the HP DMM. The heating rate was $0.1{ }^{\circ} \mathrm{C} / 3 \mathrm{~s}$ and the range was $40-67{ }^{\circ} \mathrm{C}$. A Kepko $50 \mathrm{~V}$ at $8 \mathrm{~A}$ bipolar power amplifier boosted the analogue output voltage from the temperature controller to the $24 \mathrm{~V}$ at $4 \mathrm{~A}$ maximum level required by the two TE modules wired in series.

\section{Results and Discussion}

Synthesis and Characterization. As summarized in Table 1 (column 2), the molecular weight of the PEG side chains employed was between 0 (PHEMA homopolymer) and $2080 \mathrm{~g} / \mathrm{mol}$. The success of the synthesis of the graft copolymers with varying macromolecular architecture was verified by ${ }^{1} \mathrm{H}$ NMR (methanol- $d_{4}$ ). The presence of the 2,4-dinitrophenyl protecting end group was confirmed for all of the graft copolymers by peaks present at $\delta 9.1,8.5$, and $8.1 \mathrm{ppm}$ corresponding to the protons at positions 1,2 , and 3 shown in the chemical structure of Figure 1, which also shows an example of the ${ }^{1} \mathrm{H}$ NMR data in this $\mathrm{ppm}$ region for the thiolprotected poly(HEMA-g-EG) $54 \mathrm{~K}$ graft copolymer. Treatment with mercaptoethanol resulted in the disappearance of these peaks, indicating the removal of the protecting group, while the rest of the peaks in the spectra (described following) remained unchanged. The main chain and side chain structures of the graft copolymers were verified as shown in the ${ }^{1} \mathrm{H}$ NMR spectra of Figure 2a (methanol- $\left.d_{4}\right): \delta=4.0\left(-\mathrm{CH}_{2}-\right.$ $\mathrm{OCO}), 3.8\left(-\mathrm{CH}_{2}-\mathrm{OH}\right), 2.2-1.4\left(-\mathrm{CH}_{2}-\mathrm{C}\right), 3.6(-\mathrm{O}-$ $\left.\mathrm{CH}_{2}-\mathrm{CH}_{2}-\mathrm{O}-\right), 1.3-0.7\left(-\mathrm{CH}_{3}\right) \mathrm{ppm}$.

By setting the integrated area at peak 1,2 , or 3 as a unit, the integrated areas at peaks 4 or 5 give half of the number of 2-hydroxyethyl groups. Thus, the corresponding molecular weight of the HEMA portion of the backbone of the polymer could be obtained. The PEG graft density was defined as $A / B=\mathrm{mol}$ of PEG/mol of HEMA $=N_{\mathrm{PEG}} / \mathrm{DP}_{\mathrm{n}, \mathrm{HEMA}}$ where $N_{\mathrm{PEG}}$ is the average number of PEG chains per PHEMA chain and $\mathrm{DP}_{\mathrm{n}, \mathrm{HEMA}}$ is the number-average degree of polymerization of the PHEMA backbone. The PEG graft density was obtained by the following equations: $A=\left(A_{6}+A_{7}\right) / 4 n_{\mathrm{EG}}$ which is the ratio of $1 / 4$ of the integrated area of peaks $6+7$ (since peaks 6 and 7 form one overlapping peak) divided by $n_{\mathrm{EG}}$ which is the known number of EG monomers per PEG chain and $B=\left(A_{4} / 2\right)=\left(A_{5} / 2\right)$ which is half of the integrated area of peak 4 or 5 . The total molecular weight was calculated from the molecular weight of the HEMA backbone and PEG graft density which yielded the total molecular weight of the polymer. The numberaverage molecular weight, $M_{\mathrm{n}}$, for the graft copolymers ranged between 16 and $142 \mathrm{~kg} / \mathrm{mol}$ and the ratio of the number-average degree of polymerization of EG to HEMA, $\mathrm{DP}_{\mathrm{n}, \mathrm{EG}} / \mathrm{DP}_{\mathrm{n}, \mathrm{HEMA}}$, ranged between 0 and 4.5. The PEG side chain graft density ranged between $0 \%$ (PHEMA homopolymer) and 23\%. A summary of the parameters describing the macromolecular architecture of the polymers synthesized is given in Table 1 and corresponding schematics are given in Figure $2 b$.

Cloud Point Temperature Measurements. The raw data from the cloud point temperature measurements of the graft copolymers are given in Figure 3a and the last column of Table 1 . The SH-PHEMA ${ }_{61 \mathrm{~K}}$ $\left(\mathrm{DP}_{\mathrm{n}, \mathrm{HEMA}}=469\right)$ homopolymer was insoluble through the entire temperature range probed in the cloud point measurements $\left(40-67{ }^{\circ} \mathrm{C}\right)$. While PHEMA gels are known to attain a relatively large degree of water hydration (up to $\sim 42 \%)^{21}$ at room temperature, linear PHEMA homopolymer with $\mathrm{DP}_{\mathrm{n}, \mathrm{HEMA}}=40$ starts to exhibit insoluble fractions ${ }^{18}$ (consistent with our data). The insolubility of higher molecular weight PHEMA is presumably due to attractive intramolecular interactions outweighing intermolecular bonding with water. 
<smiles>O=C(OCCSc1ccc([N+](=O)[O-])cc1[N+](=O)[O-])C12CCC1C2</smiles>

methanol-d 4

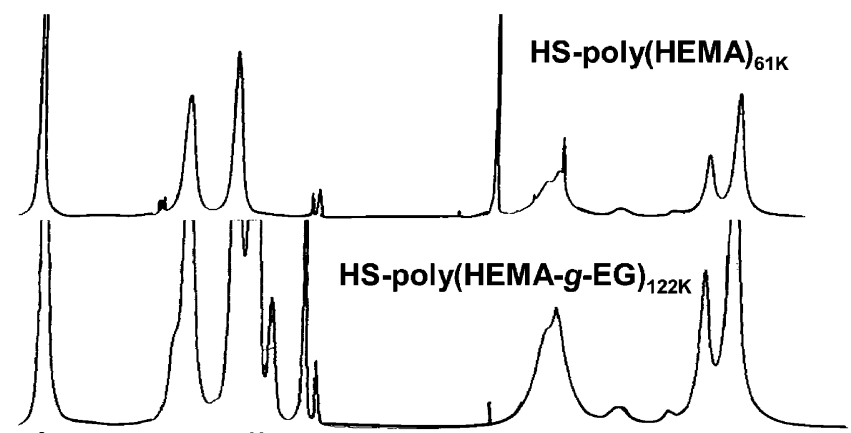

b
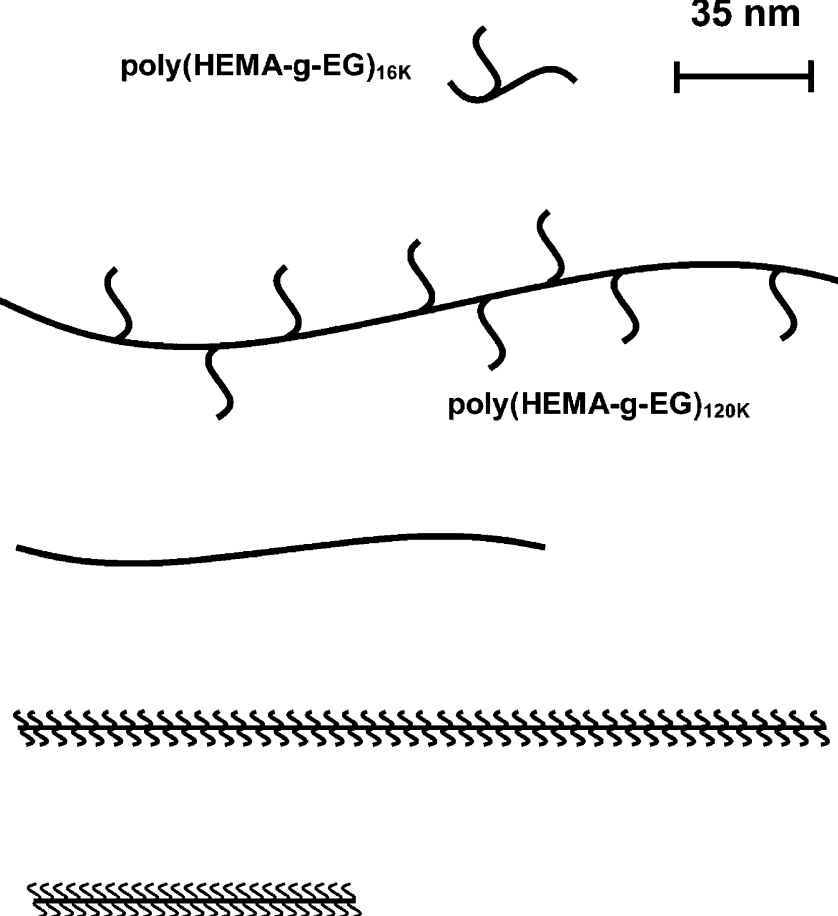

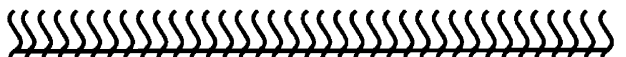
(3)
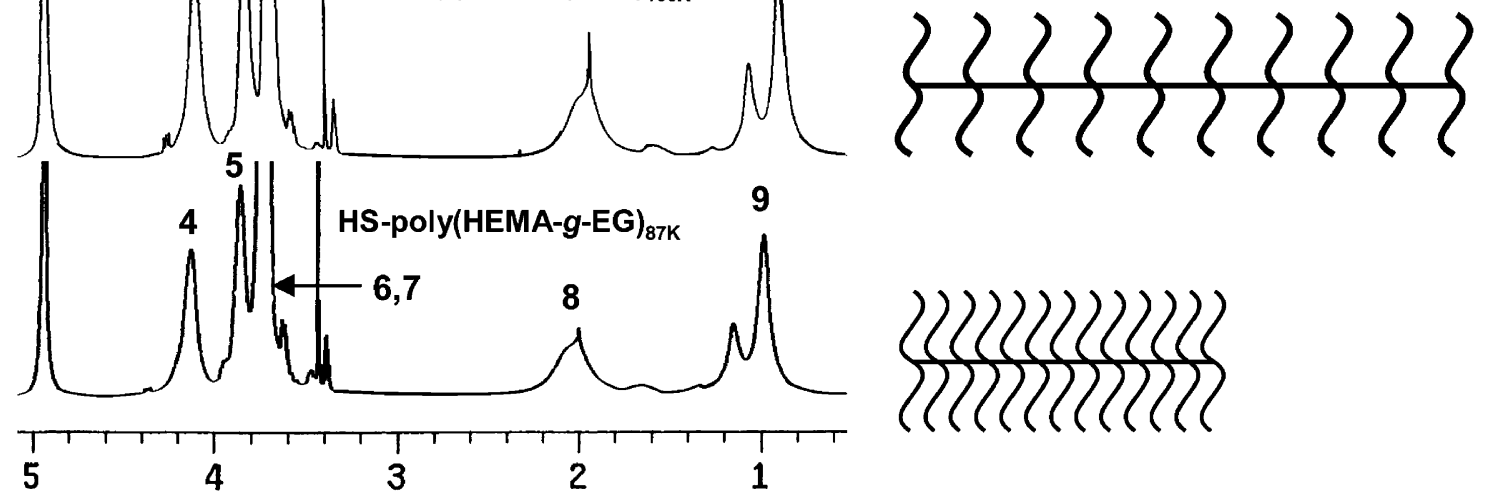

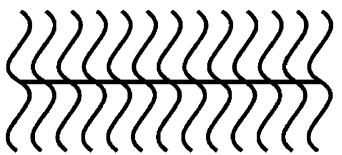

Figure 2. (a) Chemical structure (top) and ${ }^{1} \mathrm{H}$ nuclear magnetic resonance (NMR) spectra between $\delta=0.6-5 \mathrm{ppm}$ for the thiolprotected poly (2-hydroxyethyl methacrylate) $\left(\right.$ PHEMA $\left._{61 \mathrm{~K}}\right)$ and poly(2-hydroxyethyl methacrylate-g-ethylene glycol) (poly(HEMAg-EG)) graft copolymers synthesized in this study. The numerical subscript in the abbreviated polymer name labels refer to the number-average molecular weight, $M_{\mathrm{n}}$, of the graft copolymer in $\mathrm{g} / \mathrm{mol}$ and " $\mathrm{K}$ " is an abbreviation for 1000 . The peak numbers labeled on the lowermost NMR spectra (poly(HEMA-g-EG) 87K ) correspond to the protons labeled in the chemical structure at the top of Figure. The ${ }^{1} \mathrm{H}$ NMR spectra for the poly(HEMA-g-EG) $)_{120 \mathrm{~K}}$ and poly(HEMA-g-EG) $)_{16 \mathrm{~K}}$ were reported previously ${ }^{6}$ and, hence, are not shown here again. (b) Schematics of poly(HEMA-g-EG) graft copolymers synthesized in this study and previously ${ }^{6}$ with contour length dimensions for HEMA backbone, PEG side chains, and PEG side chain density drawn approximately to scale (the schematics are not meant to indicate the actual spatial distribution of PEG side chains along the HEMA backbone or the conformation of the polymer chains). Each polymer schematic is positioned horizontally across from its respective ${ }^{1} \mathrm{H}$ NMR spectrum.

Possible attractive intramolecular interactions, based on the chemical structure of PHEMA, include hydrophobic interactions between $-\mathrm{CH}_{2}-$ groups, dispersive van der Waals attractive interactions (it is reported to have a high refractive index of $1.512^{22}$ ), and it hydrogen bonds with itself via the $-\mathrm{OH}$ and $-\mathrm{O}-\mathrm{C}=\mathrm{O}$ groups.

The addition of PEG side chains and the specific macromolecular topology had a dramatic effect on the solubility of the graft copolymers, with solubility at room temperature in phosphate buffered saline solution observed for $\mathrm{DP}_{\mathrm{n}, \mathrm{EG}} / \mathrm{DP}_{\mathrm{n}, \mathrm{HEMA}}>0.4$ and an increase in cloud point temperature (representing increased solubility) with $\mathrm{DP}_{\mathrm{n}, \mathrm{EG}} / \mathrm{DP}_{\mathrm{n}, \mathrm{HEMA}}$ and molecular weight of the PEG side chains for constant $\mathrm{DP}_{\mathrm{n}, \mathrm{EG}} / \mathrm{DP}_{\mathrm{n}, \mathrm{HEMA}}$ (Figure $3 \mathrm{~b}$ and Table 1). The graft copolymers which were soluble at room temperature exhibited inverse temper- 

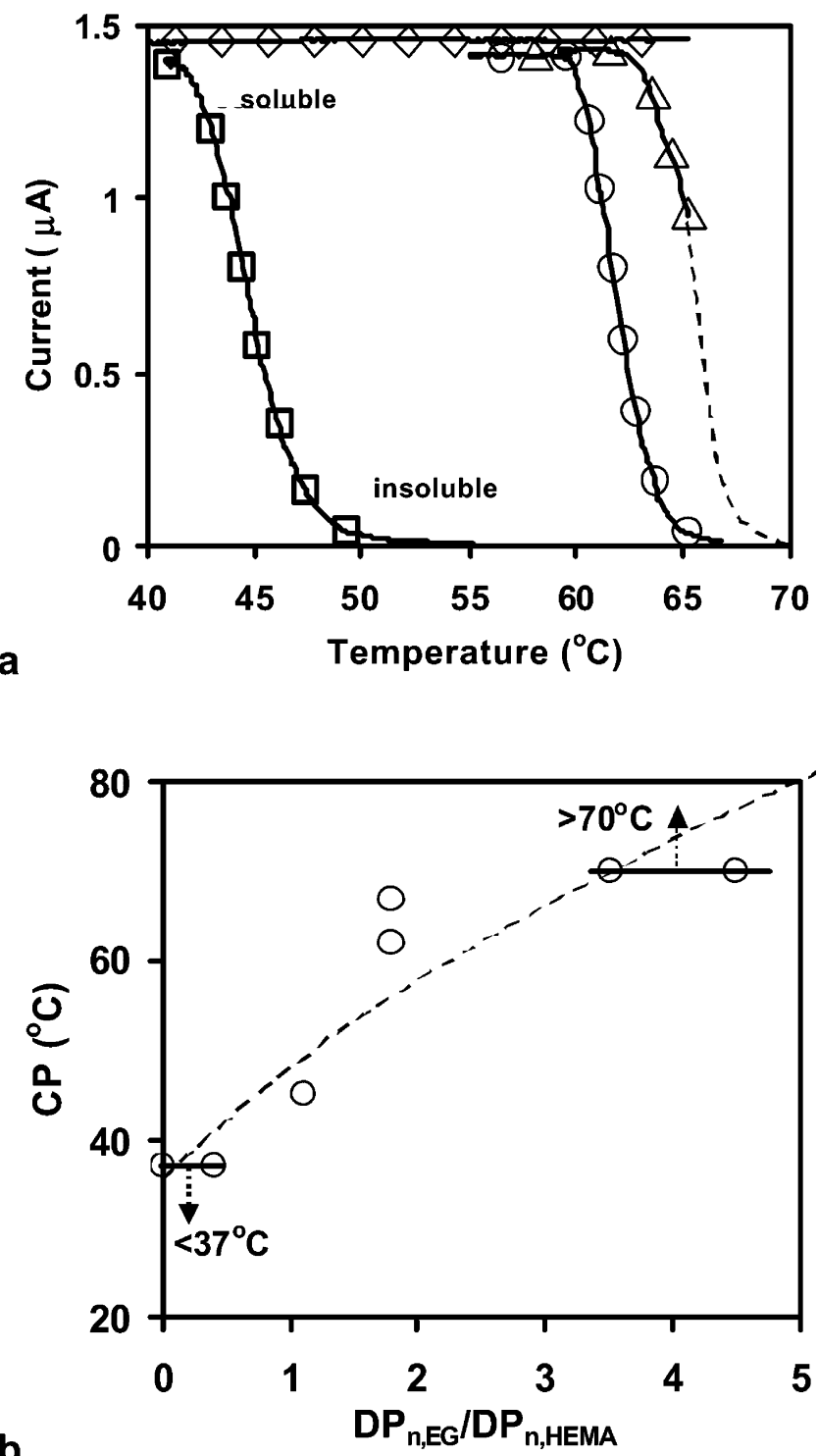

Figure 3. Cloud point temperature measurements of thiolterminated poly(2-hydroxyethyl methacrylate-g-ethylene glycol) (SH-poly(HEMA-g-EG)) graft copolymers. (a) Raw data for $(\diamond)$ Milli-Q water, ( $\square)$ SH-poly(HEMA-g-EG) ${ }_{122 \mathrm{~K}}(\mathrm{O}) \mathrm{SH}-$ poly$(\text { HEMA- } g \text {-EG) })_{54 \mathrm{~K}}$, and $(\triangle)$ SH-poly(HEMA- $g$-EG) $)_{106 \mathrm{~K}}$ in phosphate buffered saline solution. For clarity, only selected data points are shown as symbols ( $\sim 200$ data points were taken in total and are connected by the solid lines). For the SH-poly(HEMA-g-EG) $106 \mathrm{~K}$ graft copolymer the dashed line represents an extrapolation of the data to higher temperatures based on the functional form of the SH-poly(HEMA-g-EG) ${ }_{122 \mathrm{~K}}$ and SHpoly(HEMA-g-EG) $)_{54 \mathrm{~K}}$ data, since the upper temperature limit of the cloud point apparatus was $65{ }^{\circ} \mathrm{C}$. (b) Cloud point temperatures $(\mathrm{CP})$ as a function of $\mathrm{DP}_{\mathrm{n}, \mathrm{EG}} / \mathrm{DP}_{\mathrm{n}, \mathrm{HEMA}}$ in phosphate buffered saline solution where $\mathrm{DP}_{\mathrm{n}}$ is the numberaverage degree of polymerization. The numerical subscript in the abbreviated polymer names refer to the number-average molecular weight, $M_{\mathrm{n}}$, of the graft copolymer in $\mathrm{g} / \mathrm{mol}$ and "K" is an abbreviation for 1000 . The cloud point temperature was taken at $50 \%$ of the starting current signal in the raw data plots of part a. The dashed line is an empirical best fit curve to the data to guide the eye $\left(y=\sqrt{A-(x-B)^{2}}, A=271254\right.$, $B=520, R^{2}=0.85$ ).

ature solubility (Figure 3a), similar to lower molecular weight PHEMA (cloud point temperatures $\sim 28-39{ }^{\circ} \mathrm{C}$ in dilute aqueous solutions at $\mathrm{pH} 6.5^{18}$ ) and $\mathrm{PEG}$ homopolymers. ${ }^{23}$ For PEG, this interesting behavior has been explained in terms of entropic effects of fitting $\mathrm{PEO}$ molecules into the water network, ${ }^{24}$ conformation- dependent hydrophobicity, ${ }^{25}$ and competititive etherwater and water-water H-bonding. ${ }^{26}$

\section{Conclusions}

In this paper, we report the synthesis of a series of neutral SH-poly(HEMA-g-EG) comb-type graft copolymers with varying macromolecular architecture: $\mathrm{MW}_{\mathrm{PEG}}=0-2080 \mathrm{~g} / \mathrm{mol}, \mathrm{PEG}$ graft densities $=0-23 \%$, $M_{\mathrm{n}}=16-142 \mathrm{~kg} / \mathrm{mol}$, and $\mathrm{DP}_{\mathrm{n}, \mathrm{EG}} / \mathrm{DP}_{\mathrm{n}, \mathrm{HEMA}}=0-4.5$. The graft copolymers were found to be insoluble in dilute aqueous solution for $\mathrm{DP}_{\mathrm{n}, \mathrm{EG}} / \mathrm{DP}_{\mathrm{n}, \mathrm{HEMA}}<0.4$ and have an inverse temperature solubility with a cloud point temperature that increased (representing increased solubility) with $\mathrm{DP}_{\mathrm{n}, \mathrm{EG}} / \mathrm{DP}_{\mathrm{n}, \mathrm{HEMA}}$ and molecular weight of the PEG side chains for constant $\mathrm{DP}_{\mathrm{n}, \mathrm{EG}} /$ $\mathrm{DP}_{\mathrm{n}, \mathrm{HEMA}}$. This study demonstrates that dramatic differences in intramolecular interactions and macromolecular properties can be obtained via variations in topology in a neutral, water-soluble system.

Acknowledgment. The authors wish to thank NSFPECASE (0094194) and a 3M innovation fund for financial support, Professor Anne M. Mayes' group (Department of Materials Science and Engineering at MIT) for providing GPC assistance, and David Bono for cloud point apparatus construction, for measurement training, and for providing the experimental description of the apparatus.

\section{References and Notes}

(1) Ng, L. J.; Plaas, A. H. K.; Sandy, J. D.; Grodzinsky, A. J.; Ortiz, C. J. Struct. Biol. 2003, 143, 242-257.

(2) Saariaho, M.; Subbotin, A.; Szleifer, I.; Ikkala, O.; ten Brinke, G. Macromolecules 1999, 32, 4439-4443.

(3) Sheiko, S. S.; Moller, M. Chem. Rev. 2001, 101, 4099-4124.

(4) Stephan, T.; Muth, S.; Schmidt, M. Macromolecules 2002, $35,9857-9860$.

(5) Subbotin, A.; Saariaho, M.; Ikkala, O.; ten Brinke, G. Macromolecules 2000, 33, 3447-3452.

(6) Zhang, D.; Ortiz, C. Macromolecules 2004, 37, 4271-4282.

(7) Mathur, A. M.; Drescher, B.; Scranton, A. B.; Klier, J. Nature (London) 1998, 392, 367-370.

(8) Matyjaszewski, K.; Coessens, V.; Nakagawa, Y.; Xia, J.; Qiu, J.; Gaynor, S.; Coca, S.; Jasieczek, C. In Functional Polymers: Modern Synthetic Methods and Novel Structures; Patil, A. O., Schulz, D. N., Novak, B. M., Eds.; American Chemical Society: Washington, DC, 1998; p 16.

(9) Shaltiel, S. Biochem. Biophys. Res. Commun. 1967, 29, 178183.

(10) Harris, J. M., Ed. Poly(ethylene glycol) Chemistry: Biotechnical and Biomedical Applications; Plenum: New York, 1992.

(11) Ghi, P. Y.; Hill, D. J. T.; Whittaker, A. K. Biomacromolecules 2001, 2, 504-510.

(12) Oesterhelt, F.; Rief, M.; Gaub, H. E. New J. Phys. 1999, 1, $6.1-6.11$

(13) Sung, Y. K.; Gregonis, D. E.; Jhon, M. S.; Andrade, J. D. J. Appl. Polym. Sci. 1981, 26, 3719-3728.

(14) Rixman, M. A.; Dean, D.; Ortiz, C. Langmuir 2003, 19 9357-9372.

(15) Han, S.; Hagiwara, M.; Ishizone, T. Macromolecules 2003 $36,8312-8319$.

(16) Okano, T.; Uruno, M.; Sugiyama, N.; Shimada, M.; Shinohara, I.; Kataoka, K.; Sakurai, Y. J. Biomed. Mater. Res. 1986, 20, 1035-1047.

(17) Liu, S.; Weaver, J. V. M.; Save, M.; Armes, S. P. Langmuir 2002, 18, 8350-8357.

(18) Weaver, J. V. M.; Bannister, I.; Robinson, K. L.; BoriesAzeau, X.; Armes, S. P.; Smallridge, M.; McKenna, P. Macromolecules 2004, 37, 2395-2403.

(19) Save, M.; Weaver, J. V. M.; Armes, S. P.; McKenna, P. Macromolecules 2002, 35, 1152-1159.

(20) Robinson, K. L.; Khan, M. A.; de Paz Banez, M. V.; Wang, X. S.; Armes, S. P. Macromolecules 2001, 34, 3155-3158. 
(21) Pinchuk, L.; Eckstein, E. C.; van der Mark, M. R. J. Biomed. Mater. Res. 1984, 18, 671-684.

(22) Seferis, J. C. In Polymer Handbook, 4th ed.; Brandrup, J.; Immergut, E. H.; Grulke, E. A., Eds.; Wiley-Interscience: New York, 1999; p pVI 582

(23) Saeki, S.; Kuwahara, N.; Nakata, M.; Kaneko, M. Polymer 1976, $17,685-689$.
(24) Kjellander, R.; Florin, E. J. Chem. Soc., Faraday Trans. $1981,77$.

(25) Andersson, M.; Karlstrom, G. J. Phys. Chem. 1985, 89, 4957-4962.

(26) Dormidontova, E. E. Macromolecules 2002, 35, 987-1001. MA049330K 